\title{
Chronicity factors of temporomandibular disorders: a critical review of the literature
}

\section{Maísa Soares GUI(a) Célia Marisa RIZZATTI-BARBOSA(b)}

(a) Universidade Estadual de Campinas UNICAMP, Piracicaba Dental School, Department of Anatomy, Piracicaba, SP, Brazil.

(b) Universidade Estadual de Campinas - UNICAMP, Piracicaba Dental School, Department of Prosthesis and Periodontology, Piracicaba, SP, Brazil.
Declaration of Interests: The authors certify that they have no commercial or associative interest that represents a conflict of interest in connection with the manuscript.

Corresponding Author:

Maísa Soares Gui

E-mail:maisa_gui@yahoo.com.br

DOI: 10.1590/1807-3107BOR-2015.vol29.0018

Submitted: Apr 07, 2014

Accepted for publication: Sep 14, 2014

Last revision: Nov 27, 2014
Abstract: Facial pain often persists long after any identifiable organic pathology has healed. Moreover, in a subgroup of patients with temporomandibular disorder (TMD), no treatment is effective. Knowledge of factors associated with persistent pain in TMD could help identify personalized treatment approaches. Therefore, we conducted a critical review of the literature for the period from January 2000 to December 2013 to identify factors related to TMD development and persistence. The literature findings showed that chronic TMD is marked by psychological distress (somatization and depression, affective distress, fear of pain, fear of movement, and catastrophizing) and characteristics of pain amplification (hyperalgesia and allodynia). Furthermore, these factors seem to interact in TMD development. In addition, our review demonstrates that upregulation of the serotonergic pathway, sleep problems, and gene polymorphisms influence the chronicity of TMD. We conclude that psychological distress and pain amplification contribute to chronic TMD development, and that interactions among these factors complicate pain management. These findings emphasize the importance of multidisciplinary assistance in TMD treatment.

Keywords: Craniomandibular Disorders; Chronic Pain; Facial Pain.

\section{Introduction}

Temporomandibular disorder (TMD)-associated pain is the third most prevalent chronic pain condition worldwide, after tension headaches and back pain. ${ }^{1}$ Chronic facial pain, including pain associated with TMD, is most often caused by myoarthropathy of the masticatory system. ${ }^{2}$ Despite the prevalence of TMD, factors involved in the transition from the acute to the chronic phase of the disorder remain unclear.

Chronic TMD occurs in a subgroup of TMD patients who, unlike other TMD patients, do not respond to treatment. These "nonresponders" have higher depression, pessimism, and catastrophizing scores and lower self-efficacy and coping scores than their peers. ${ }^{3}$

Researchers have proposed a heuristic model of causal influences that contribute to the onset and persistence of TMD and related conditions. ${ }^{4}$ This model includes two principal intermediate phenotypes: psychological distress and pain amplification. ${ }^{4}$ Psychological distress is believed to result from the discomfort and frustration associated with the disorder, and it has a bidirectional role in TMD pain. ${ }^{5}$ Pain amplification refers to alterations in peripheral and central nervous system processes that have 
the net effect of amplifying the perceptual response to nociceptive stimuli (e.g., hyperalgesia, allodynia). ${ }^{4}$

Pain of this nature and preoccupation with pain often lead to major distress, suffering, and functional disability, which are associated with inappropriate use of medical services and high-cost insurance claims. ${ }^{6}$ Furthermore, in patients with chronic TMD, it is difficult to determine what type of care will or will not work for each patient. Knowledge of factors associated with TMD persistence and treatment approaches that emphasize flexibility to meet a patient's individual needs could represent a new direction in the treatment of TMD-related pain. ${ }^{3}$ Therefore, the objective of our literature review was to identify factors related to TMD development and persistence.

\section{Methodology}

A literature search was performed of electronic bibliographic databases (Medline, PubMed, and LILACS) for the period between January 2000 and December 2013. The following keywords were used: temporomandibular disorders and chronic facial pain combined with: catastrophizing, coping behavior, emotional stress, somatization disorder, affective disorders, depression, hyperalgesia, pain threshold, central sensitization, or sleep disorders.

Two independent reviewers read the obtained abstracts and, by consensus, selected articles that met the following inclusion criteria: patients with TMD diagnosis and chronic facial pain. The reviewers read the selected articles and evaluated them for inclusion in the literature review. Additional inclusion criteria for the research articles were as follows: investigations of the relationship between psychological distress and TMD, and investigations about pain amplification in TMD.

All research articles included in the review had a sample population aged 18 years or older with subjects of both sexes. Of the initial 977 abstracts found (524 related to psychological distress and 453 related to pain amplification), 789 were excluded. Excluded abstracts were those of repeated studies and studies with unrelated scopes. The remaining 188 articles were read in their entirely. Then, 150 studies were excluded because they were not clearly related to the review topics. Most of the 38 selected studies had cross-sectional study designs (only one study had a prospective design).

\section{Results Psychological Distress}

In TMD, psychosocial factors have been associated with the severity of clinical symptoms ${ }^{7}$ and pain chronification. ${ }^{8}$ Multiple psychological factors have been implicated as potential risk factors for the development of painful TMD. ${ }^{4}$ Main literature findings about the relationship between psychological distress and TMD are presented in Table 1.

\section{Global Measures of Psychological Function}

Somatization and depression are examples of global psychological symptoms. A recent study, ${ }^{9}$ which examined TMD patients of different cultures from widely separated clinical sites, reported a prevalence of severe somatization of $28.5 \%$. Prevalence of severe depression increased with the rate of pain-related impairment, ranging from $16.7 \%$ in TMD patients with no disability to $53.8 \%$ in patients with high disability and severely limiting impairments. ${ }^{9}$ However, it is unclear whether depression and somatization are derived from chronic pain or whether they are risk factors for the development of chronic pain. ${ }^{10}$

\section{Affective Distress and Psychosocial Stress}

Anxiety is a relatively permanent state of worry and nervousness characterized by physical symptoms, which are usually accompanied by compulsive behaviors or panic attacks. ${ }^{11}$ Anxiety levels are correlated with facial pain, and TMD patients who are more anxious seem to be at greater risk of developing chronic pain. ${ }^{12,13}$ Anxiety sensitivity is defined as the fear of anxiety symptoms (e.g., palpitations, dizziness, gastrointestinal upset). ${ }^{6}$ Elevated levels of anxiety about pain and fear of pain contribute to disability and interfere with life activities. ${ }^{14}$

If pain is interpreted as threatening (pain catastrophizing), then pain-related fear evolves. Pain-related fear leads to avoidance/escape, followed by disability, disuse, and depression. Depression maintains pain experiences, thereby fueling a vicious circle of increasing fear and avoidance. In patients who do not catastrophize, pain-related fear is unlikely to occur. These patients are expected to confront daily activities rapidly, leading to fast recovery. ${ }^{15,16}$ Among the psychological determinants of TMD persistence, 
Table 1. Literature findings about psychological distress and TMD.

\begin{tabular}{|c|c|c|c|}
\hline Author & Construct (Questionnaire) & Study Design & Main Findings \\
\hline McNeil et al. ${ }^{16}$ (2001) & $\begin{array}{c}\text { Fear of pain } \\
\text { (Fear of Pain Questionnaire) }\end{array}$ & $\begin{array}{l}\text { Cross-sectional } \mathrm{N}=40 \\
\text { facial pain and } 40 \text { matched } \\
\text { controls. }\end{array}$ & $\begin{array}{l}\text { Facial pain patients reported greater fear of severe } \\
\text { pain. }\end{array}$ \\
\hline Turner et al. ${ }^{30}$ (2001) & $\begin{array}{l}\text { Coping, and catastrophizing } \\
\text { (Coping Strategies } \\
\text { Questionnaire) }\end{array}$ & $\begin{array}{l}\text { Cross-sectional. } \mathrm{N}=118 \\
\text { TMD. }\end{array}$ & $\begin{array}{l}\text { Significant associations between depression, and non- } \\
\text { masticatory jaw activity limitations; catastrophizing and } \\
\text { activity interference and also coping. }\end{array}$ \\
\hline Visscher et al. ${ }^{17}(2010)$ & $\begin{array}{l}\text { Fear of movement } \\
\text { (TSK-TMD) }\end{array}$ & $\begin{array}{c}\text { Cross-sectional. } \mathrm{N}=301 \\
\text { TMD. }\end{array}$ & $\begin{array}{l}\text { Fear of movement was related to pain, joint sounds, } \\
\text { and jaw locking. }\end{array}$ \\
\hline Manfredini et al. ${ }^{9}(2010)$ & $\begin{array}{l}\text { Depression and Somatization } \\
\text { (Symptoms Checklist-90) }\end{array}$ & $\begin{array}{c}\text { Cross-sectional. } \mathrm{N}=1,149 \\
\text { TMD. }\end{array}$ & $\begin{array}{l}\text { Pain-related disability was strongly related with } \\
\text { depression and somatization as well as associated } \\
\text { with pain duration. }\end{array}$ \\
\hline Park et al. ${ }^{33}(2010)$ & $\begin{array}{l}\text { Depression, Somatization } \\
\text { (RDC/TMD) }\end{array}$ & $\begin{array}{l}\text { Case-control } \mathrm{N}=36 \\
\text { controls and } 39 \mathrm{TMD} \text {. }\end{array}$ & $\begin{array}{l}\text { Every score of the psychological profiles was higher } \\
\text { for TMD. }\end{array}$ \\
\hline Monteiro et al. ${ }^{13}$ (201 1) & $\begin{array}{l}\text { Trait-anxiety and State-anxiety } \\
\text { (State-Trait Anxiety Inventory) }\end{array}$ & $\begin{array}{l}\text { Case-control } N=101 \\
\text { controls and } N=49 T M D \text {. }\end{array}$ & $\begin{array}{l}\text { The correlation between trait-anxiety levels and chronic } \\
\text { facial pain degrees was significant and positive. }\end{array}$ \\
\hline Fillingim et al. ${ }^{7}(2011)$ & $\begin{array}{l}\text { Somatic Awareness (PILL and } \\
\text { SCL-90R-Somatization). }\end{array}$ & $\begin{array}{l}\text { Case-control } \mathrm{N}=3,263 \\
\text { controls and } 185 \mathrm{TMD} \text { cases. }\end{array}$ & $\begin{array}{l}\text { TMD cases reported higher levels of increased } \\
\text { somatic awareness. }\end{array}$ \\
\hline Kim et al. ${ }^{32}$ (2012) & $\begin{array}{l}\text { Depression and Somatization } \\
\text { (RDC/TMD) }\end{array}$ & $\begin{array}{l}\text { Cross-sectional. } \mathrm{N}=317 \\
\text { TMD. }\end{array}$ & $\begin{array}{l}\text { Myofascial pain group showed more severe } \\
\text { depressive and nonspecific physical symptoms than } \\
\text { internal derangement group. }\end{array}$ \\
\hline
\end{tabular}

there is increasing evidence that fear ${ }^{17,18}$ and fear of movement are predictive of future perceived disability. ${ }^{19}$ An analysis using the Tampa Scale for Kinesiophobia for TMD (TSK-TMD) showed that TMD functional problems were strongly associated with activity avoidance, but not with somatic focus. ${ }^{17}$

\section{Coping and Catastrophizing}

Coping strategies are defined as constantly changing cognitive and behavioral efforts to manage specific external and/or internal demands. ${ }^{20,21}$ Catastrophizing is defined as expecting or worrying about major negative consequences of a situation, even one of minor importance. ${ }^{20,22}$ Recent findings in chronic TMD patients indicated that treatment nonresponders, who accounted for $16 \%$ of the sample, reported more psychiatric symptoms, poorer coping, and higher levels of catastrophizing than patients who responded to treatment. ${ }^{3}$

\section{Pain Amplification}

Main findings from the literature about pain amplification are presented in Table 2. Multiple bodily pain conditions in TMD have been associated with generalized alterations in pain processing. ${ }^{23}$ However, it is not fully understood which parts of the peripheral or central nervous systems play a role when hyperalgesia becomes maladaptive rather than protective. ${ }^{24}$ Moreover, for reasons still unknown, TMD can manifest as localized pain or in conjunction with widespread pain. ${ }^{25}$

One study suggested that primary insomnia might share a common substrate underlying central sensitivity or play a causal role in the development of hyperalgesia in TMD patients. ${ }^{26}$ Researchers have distinguished between TMD as a regional or widespread pain syndrome on the basis of the identification of a "sensitive" TMD subgroup that had symptoms resembling fibromyalgia and differed from an "insensitive" TMD subgroup. ${ }^{27}$ Mechanisms contributing to pain amplification include decreased function in pain inhibitory systems and enhancement of pain facilitatory pathways. Pain amplification may be both an inherited trait and a phenotype that can develop over time in response to emergent biological processes or environmental exposures. ${ }^{4}$

People with localized TMD differed from healthy controls in their allelic frequency of single nucleotide polymorphisms that mapped to a serotonergic receptor pathway, suggesting that upregulation of the serotonergic pathway may play a role in this condition ${ }^{28}$. Consistent with this possibility, 
Table 2. Literature findings about pain amplification and TMD.

\begin{tabular}{|c|c|c|c|}
\hline Author & Measurements & Study Design & Main Findings \\
\hline Smith et al. ${ }^{26}(2009)$ & $\begin{array}{l}\text { Laboratory measures } \\
\text { of pain sensitivity and } \\
\text { polysomnography }\end{array}$ & $\begin{array}{l}\text { Cross-sectional. } \mathrm{N}=53 \\
\text { myofascial TMD. }\end{array}$ & $\begin{array}{l}\text { Primary insomnia was associated with hyperalgesia } \\
\text { at a non-orofacial site. }\end{array}$ \\
\hline Pfau et al. ${ }^{27}$ (2009) & $\begin{array}{l}\text { Tender point, and } \\
\text { quantitative sensory testing } \\
\text { profiles. }\end{array}$ & $\begin{array}{l}\text { Case-control } \\
\mathrm{N}=23 \mathrm{TMD} \cdot \mathrm{N}=18 \\
\text { fibromyalgia. }\end{array}$ & $\begin{array}{l}\text { They found an insensitive subgroup resembling } \\
\text { healthy controls and a sensitive TMD subgroup } \\
\text { resembling fibromyalgia patients. }\end{array}$ \\
\hline Park et al. ${ }^{33}(2010)$ & $\begin{array}{c}\text { Thermal pain sensitivity } \\
\text { threshold. }\end{array}$ & $\begin{array}{l}\text { Case-control } N=36 \\
\text { normal and } 39 \text { TMD. }\end{array}$ & TMD patients were more sensitive to thermal pain. \\
\hline Sipilä et al. ${ }^{38}(2011)$ & $\begin{array}{l}\text { Muscle and Joint } \\
\text { standardized palpation. }\end{array}$ & $\begin{array}{c}\text { Cross-sectional. } \mathrm{N}=6,227 \\
\text { TMD. }\end{array}$ & $\begin{array}{l}\text { Masticatory muscle pain and TMD joint pain was } \\
\text { associated with back, neck and shoulder pain. }\end{array}$ \\
\hline Chen et al. ${ }^{23} 2012$ ) & $\begin{array}{l}\text { Heat and Pressure pain } \\
\text { thresholds (PPT). }\end{array}$ & $\begin{array}{l}\text { Case-control } N=76 \\
\text { TMD with widespread body } \\
\text { pain (WPT), } N=83 \text { TMD, } \\
\quad N=181 \text { controls. }\end{array}$ & $\begin{array}{l}\text { TMD with WPT presented with reduced PPT in cranial } \\
\text { and extracranial regions compared to TMD without } \\
\text { WPT. Heat pain tolerance was slightly lower. }\end{array}$ \\
\hline
\end{tabular}

individuals with localized TMD reported less depressive symptoms compared to patients with TMD and widespread pain. ${ }^{28}$ Another study ${ }^{29}$ proposed that negative affect and genetics (serotonin transporter polymorphisms) lead to disrupted sleep via an increase in stress reactivity. The interaction of these variables led to an increase in learned negative associations, which, in turn, increased the likelihood of developing poor sleep and insomnia, which are common TMD phenotypes.

\section{Discussion}

This review of the literature shows that chronic TMD is marked by psychological distress and pain amplification, and that these factors appear to interact with each other. Moreover, upregulation of the serotonergic pathway, sleep problems, and gene polymorphisms influence the development of chronic TMD.

Physiological distress has been related to masticatory function, which could explain its influence on TMD chronicity. Catastrophizing measurements have been linked to greater levels of depression, activity interference, and perceived jaw interference in TMD patients. ${ }^{3}$ However, no process variable (catastrophizing or coping) was associated with the objective measurement of jaw impairment. Beliefs and catastrophizing explained significant portions of the variance in nonmasticatory jaw activity (e.g., laughing and yawning) limitations, but none of these factors were associated with masticatory jaw activity (e.g., eating an apple) limitations. ${ }^{30}$
There were also significant positive correlations between depression and jaw amplitude, and stress and jaw velocity for standardized chewing, but not for habitual chewing. This finding suggests that psychological factors, which manifest in depression and stress, play a role in the association between pain and motor activity.

Myalgia patients may experience more stressful life circumstances and a greater negative effect of illness. ${ }^{5}$ These patients showed more severe depressive and nonspecific physical symptoms than patients with internal derangement. ${ }^{32}$ The myogenous pain subgroup had significantly higher somatization and depression scores than the normal and arthrogenous pain subgroups. ${ }^{33}$

Although pain is the major complaint of TMD patients, the presence of pain-independent functional problems is especially associated with higher levels of fear of movement. ${ }^{7}$ Pain-related fear is more disabling than pain itself and is related to poor behavioral performance. ${ }^{34} \mathrm{On}$ the other hand, patients with a positive affect, social support, adequate treatment adherence, and spirituality felt better regarding their disease conditions and, consequently, had a better quality of life. ${ }^{35}$ Pain beliefs are important predictors of treatment outcome and should be considered in the management of TMD patients. ${ }^{8}$

A prospective study showed that two risk factors for elevated TMD incidence were greater numbers of comorbid pain conditions and a greater 
extent of nonspecific orofacial symptoms. Other baseline risk factors were preexisting bodily pain, heightened somatic awareness, and greater extent of pain in response to examiners' palpation of the head, neck, and body. ${ }^{36}$ Other study showed that measures of catastrophizing and active pain coping, which are well-established constructs associated with chronic pain, were not significant predictors of the onset of TMD, but they could play a role in the perpetuation of TMD symptoms. ${ }^{37}$

Taken together, physiological distress, sleep problems, upregulation of the serotonergic pathway, and gene polymorphisms could act as chronicity factors for TMD and pain amplification because they also act as pain-perpetuating factors. These literature findings are in line with the multifactorial etiology of chronic facial pain, and shift the perspective away from a local etiology towards a more central etiology, with dysregulations in the stress and pain-modulating systems. ${ }^{2}$ Therefore, to understand how a person responds to persistent

\section{References}

1. Dworkin SF. Temporomandibular disorder (TMD) painrelated disability found related to depression, nonspecific physical symptoms, and pain duration at 3 international sites. J Evid Based Dental Pract. 2011 Sep;11(3):143-4.

2. Galli U, Gaab J, Ettlin DA, Ruggia F, Ehlert U, Palla S. Enhanced negative feedback sensitivity of the hypothalamus-pituitaryadrenal axis in chronic myogenous facial pain. Euro J Pain. 2009 Jul;13(6):600-5.

3. Litt MD, Porto FB. Determinants of pain treatment response and nonresponse: identification of TMD patient subgroups. J Pain. 2013 Nov;14(11):1502-13.

4. Maixner W, Diatchenko L, Dubner R, Fillingim RB, Greenspan JD, Knott C, et al. Orofacial pain prospective evaluation and risk assessment study - the OPPERA study. J Pain. 2011 Nov;12(11 Suppl):T4-T11.e1-2.

5. McCreary CP, Clark GT, Merril RL, Flack V, Oakley ME. Psychological distress and diagnostic subgroups of temporomandibular disorder patients. Pain. 1991 Jan;44(1):29-34

6. Asmundson GJ, Norton PJ, Norton GR. Beyond pain: the role of fear and avoidance in chronicity. Clin Psychol Rev. 1999 Jan;19(1):97-119.

7. Fillingim RB, Ohrbach R, Greenspan JD, Knott C, Dubner R, Bair E, et al. Potential psychosocial risk factors for chronic TMD: pain, it is important not only to examine the physical parameters, but also to consider factors such as cognition, coping strategies, life events, and personality. ${ }^{6,38}$

\section{Conclusion}

The chronic TMD process is marked by psychological distress and pain amplification, and these factors appear to interact with one another. We conclude that psychological distress factors (e.g. somatization, catastrophizing, and depression), poor sleep, and genetic polymorphisms related to generalized alterations in pain processing are more commonly associated with TMD development and persistence than mechanical factors (e.g., clenching). Therefore, these factors have been the focus of current research.

\section{Funding Information}

Coordenação de Aperfeiçoamento de Pessoal de Nivel Superior - CAPES-Project \#A079/2013.

descriptive data and empirically identified domains from the OPPERA case-control study. J Pain. 2011 Nov;12(11 Suppl):T46-T60.

8. Galli U, Ettlin DA, Palla S, Ehlert U, Gaab J. Do illness perceptions predict pain-related disability and mood in chronic orofacial pain patients? A 6-month follow-up study. Euro J Pain. 2010 May;14(5):550-8.

9. Manfredini D, Winocur E, Ahlberg J, Guarda-Nardini L, Lobbezoo F. Psychosocial impairment in temporomandibular disorders patients. RDC/TMD axis II findings from a multicentre study. J Dent. 2010 Oct;38(10):765-72.

10. Widmer C. Depression is associated with nonspecific physical symptoms in Asian TMD patients. J Evid Based Dent Pract. 2005 Sep;5(3):168-9.

11. Giannakopoulos NN, Keller L, Rammelsberg P, Kronmüller $\mathrm{K}$, Schmitter M. Anxiety and depression in patients with chronic temporomandibular pain and in controls. J Dent. 2010 May;38(5):369-76.

12. Wright AR, Gatchel RJ, Wildenstein L, Riggs R, Buschang P, Ellis E 3rd. Biopsychosocial differences between high-risk and low-risk patients with acute TMD-related pain. J Am Dent Assoc. 2004 Apr;135(4):474-83.

13. Monteiro DR, Zuim PRJ, Pesqueira AA, Ribeiro PP, Garcia AR. Relationship between anxiety and chronic orofacial pain of temporomandibular disorder in a group of university students. J Prosthodontic Res. 2011 Jul;55(3):154-8. 
14. McCracken LM, Zayfert C, Gross RT. The Pain Anxiety Symptoms Scale: development and validation of a scale to measure fear of pain. Pain. 1992 Jul;50(1):67-73.

15. Vlaeyen JW, Vancleef LM. Movement, Stability \& Lumbopelvic Pain. 2nd ed. Edinburgh: Churchill Livingstone; 2007. Chapter 32, Behavioral analysis, fear of movement/(re)injury, and cognitive-behavioral management of chronic low back pain; p. 475-85.

16. McNeil DW, Au AR, Zvolensky MJ, McKee DR, Klineberg IJ, Ho CC. Fear of pain in orofacial pain patients. Pain. 2001 Jan;89(2-3):245-52.

17. Visscher CM, Ohrbach R, van Wijk AJ, Wilkosz M, Naeije M. The Tampa Scale for kinesiophobia for temporomandibular disorders (TSK-TMD). Pain. 2010 Sep;150(3):492-500.

18. French DJ, France CR, Vigneau F, French JA, Evans RT. Fear of movement/(re)injury in chronic pain: a psychometric assessment of the original English version of the Tampa scale for kinesiophobia (TSK). Pain. 2007 Jan;127(1-2):42-51.

19. Swinkels-Meewisse IE, Roelofs J, Schouten EG, Verbeek AL, Oostendorp RA, Vlaeyen JW. Fear of movement injury predicting chronic disabling low back pain: a prospective inception cohort study. Spine (Phila Pa 1976). 2006 Mar 15;31(6):658-64

20. Turner JA, Jensen MP, Romano JM. Do beliefs, coping, and catastrophizing independently predict functioning in patients with chronic pain?. Pain. 2000 Mar;85(1-2):115-25.

21. Lazarus RS, Folkman S. Stress, Appraisal, and Coping. New York: Springer Publishing Company; 1984. 177p.

22. Fillingim RB, Slade GD, Diatchenko L, Dubner R, Greenspan JD, Knott $C$, et al. Summary of findings from the OPPERA baseline case-control study: implications and future directions. J Pain. 2011 Nov;12(11):T102-7.

23. Chen H, Slade G, Lim PF, Miller V, Maixner W, Diatchenko L. Relationship between temporomandibular disorders, widespread palpation tenderness, and multiple pain conditions: a case-control study. J Pain. 2012 Oct;13(10):1016-27.

24. Sandkühler J. Models and mechanisms of hyperalgesia and allodynia. Physiol Rev. 2009 Apr;89(2):707-58.

25. Slade GD, Conrad MS, Diatchenko L, Rashid NU, Zhong $S$, Smith S, et al. Cytokine biomarkers and chronic pain: association of genes, transcription, and circulating proteins with temporomandibular disorders and widespread palpation tenderness. Pain. 2011 Dec;152(12):2802-12.

26. Smith MT, Wickwire EM, Grace EG, Edwards RR, Buenaver LF, Peterson S, et al. Sleep disorders and their association with laboratory pain sensitivity in temporomandibular joint disorder. Sleep. 2009 Jun;32(6):779-90.
27. Pfau DB, Rolke R, Nickel R, Treede RD, Daublaender M. Somatosensory profiles in subgroups of patients with myogenic temporomandibular disorders and Fibromyalgia Syndrome. Pain. 2009 Dec 15;147(1-3):72-83.

28. Slade GD, Smith SB, Zaykin DV, Tchivileva IE, Gibson DG, Yuryev A, et al. Facial pain with localized and widespread manifestations: separate pathways of vulnerability. Pain. 2013 Nov;154(11):2335-43.

29. Harvey CJ, Gehrman P, Espie CA. Who is predisposed to insomnia: a review of familial aggregation, stressreactivity, personality and coping style. Sleep Med Rev. 2014 Jun;18(3):237-47.

30. Turner JA, Dworkin SF, Mancl L, Huggins KH, Truelove EL. The roles of beliefs, catastrophizing, and coping in the functioning of patients with temporomandibular disorders. Pain. 2001 May;92(1-2):41-51.

31. Brandini DA, Benson J, Nicholas MK, Murray GM, Peck CC. Chewing in temporomandibular disorder patients: an exploratory study of an association with some psychological variables. J Orofac Pain. 2011 Winter;25(1):56-67.

32. Kim YK, Kim SG, Im JH, Yun PY. Clinical survey of the patients with temporomandibular joint disorders, using Research Diagnostic Criteria (Axis II) for TMD: preliminary study. J Craniomaxillofac Surg. 2012 Jun;40(4):366-72.

33. Park JW, Clark GT, Kim YK, Chung JW. Analysis of thermal pain sensitivity and psychological profiles in different subgroups of TMD patients. Int J Oral Maxillofac Surg. 2010 Oct;39(10):968-74.

34. Crombez G, Vlaeyen JWS, Heuts PHTG, Lysens R. Painrelated fear is more disabling than pain itself: evidence on the role of pain-related fear in chronic back pain disability. Pain. 1999 Mar;80(1-2):329-39.

35. Vilhena E, Pais-Ribeiro J, Silva I, Pedro L, Meneses RF, Cardoso $\mathrm{H}$, et al. Psychosocial factors as predictors of quality of life in chronic Portuguese patients. Health Qual Life Outcomes. 2014 Jan 9;12(1):3.

36. Bair E, Ohrbach R, Fillingim RB, Greenspan JD, Dubner R, Diatchenko L, et al. Multivariable modeling of phenotypic risk factors for first-onset TMD: the OPPERA prospective cohort study. J Pain. 2013 Dec;14(12 Suppl):T102-15.

37. Fillingim RB, Ohrbach R, Greenspan JD, Knott C, Diatchenko L, Dubner R, et al. Psychological factors associated with development of TMD: the OPPERA prospective cohort study. J Pain. 2013 Dec;14(12 Suppl):T75-T90.

38. Sipilä K, Suominen AL, Alanen P, Heliövaara M, Tiittanen $\mathrm{P}$, Könönen M. Association of clinical findings of temporomandibular disorders with self-reported musculoskeletal pains. Euro J Pain. 2011 Nov;15(10):1061-7. 